Iberian Journal of the History of Economic Thought

ISSN-e 2386-5768

http://dx.doi.org/10.5209//JHE.62433

\title{
Trabajo improductivo: una idea de largo recorrido
}

José Luis Ramos Gorostiza ${ }^{1}$

COSIMO PERROTTA, Unproductive labour in political economy: the history of an idea, Londres y Nueva York, Routledge, 2018, 269 páginas.

La reciente crisis económica de 2008 trajo consigo la reaparición y el uso frecuente en el lenguaje coloquial —artículos de prensa, tertulias radiofónicas, charlas informales, etc.- de expresiones tales como "actividades improductivas", "estériles" o "parasitarias". Dichas expresiones coloquiales, muy vagas o difusas en cuanto a su significado, remitían sin embargo, siquiera lejanamente, a un concepto de largo arraigo en el ámbito profesional de las ideas económicas: el trabajo improductivo. Pues bien, este excelente libro rastrea precisamente dicha idea y los conceptos a ella asociados a lo largo de la historia del pensamiento económico, desde sus primeros esbozos hasta la reciente crisis económica. Y lo hace de un modo exhaustivo y riguroso, pero manteniendo al mismo tiempo una admirable claridad. Esto último es un gran mérito dada la enorme cantidad de enfoques y matices que hacen del tema un complejo terreno pantanoso. Su autor, Cosimo Perrotta, ha sido profesor de la Universidad de Salento, en Italia, y es uno de los mayores expertos europeos en el ámbito de la historia del pensamiento económico. El presente volumen es en realidad fruto de un empeño de largo alcance, pues es continuación de un libro suyo anterior: Consumption as an Investment: I. The Fear of Goods from Hesiod to Adam Smith, Routledge, 2004.

La cuestión del trabajo improductivo desapareció del acervo conceptual de los economistas de la corriente principal desde que éstos pasaron a entender la riqueza como la suma de los ingresos individuales. Sin embargo, entre los siglos XVI y XIX dicha cuestión sí ocupó un lugar relevante en las reflexiones económicas. Mientras los economistas concibieron la riqueza social como el conjunto de recursos públicos y privados de una nación, tendieron a pensar que el trabajo improductivo no contribuía al incremento de la riqueza social ni fomentaba un mayor desarrollo económico futuro. Estaban generalmente haciendo referencia a un trabajador que producía menos riqueza — o a lo sumo la misma - que la que consumía. La economía no era para ellos una mera serie de intercambios entre individuos, sino la organización de la sociedad para la producción de riqueza social.

Aunque fue Petty quien por primera vez analizó la idea de trabajo improductivo con cierto detenimiento en el siglo XVII, serían los fisiócratas y sobre todo Smith quienes impulsarían definitivamente el uso de dicho concepto a costa de hacerlo más restrictivo y rígido. Como señala el profesor Perrotta en las conclusiones finales de su obra, ya en los economistas de la Ilustración la noción de trabajo improductivo estaba ligada a la relación entre dos factores clave del crecimiento, el consumo y el incremento de la productividad, pero - salvo en Smith- faltaba un análisis del proceso de acumulación de capital. Serían los autores clásicos quienes intentarían examinar con detalle la influencia del consumo de los trabajadores en la acumulación (que conllevaba el problema de las crisis) y el crecimiento de la riqueza inmaterial (ligado al crecimiento del capital humano y el consecuente aumento de la productividad). No obstante, ambos análisis se vieron truncados por su limitada concepción de los salarios y de la riqueza (que asociaban principalmente a bienes materiales). Posteriormente, la idea de trabajo improductivo ya sólo seguiría teniendo un sitio dentro de corrientes heterodoxas, pues los economistas neoclásicos la desterrarían defini- 
tivamente al tomar el ingreso como única medida de productividad (considerando que el trabajo sólo existe si proporciona una remuneración o recompensa al trabajador). Al mismo tiempo, los economistas neoclásicos encontrarían en la idea de la inversión en capital humano una potente herramienta para interpretar el vínculo entre incremento del consumo e incremento de la productividad, pero - al aplicarla sólo a nivel individual — dejarían de lado su potencial para desentrañar los complejos problemas de la acumulación de capital y explicar posibles causas y remedios de las crisis económicas.

En la parte final de su trabajo (capítulos XIX a XXI), el profesor Perrotta concluye que sería conveniente recuperar la idea del empleo productivo del capital y del trabajo, delimitándola dentro de un marco conceptual adecuado, para ganar en capacidad explicativa. En su opinión, el declive de las economías maduras que siguió al periodo de apogeo del Estado del Bienestar se debe precisamente a la saturación. Es decir, en vez de abrir nuevos campos de inversión vinculados al capital humano, los bienes colectivos y las infraestructuras, la persistencia de la inversión en sectores ya saturados ha conducido a una situación de más desempleo, explotación laboral, pobreza y desigualdad.

En definitiva, estamos ante una obra de alta calidad y llena de ideas sugerentes que, pese a adoptar una perspectiva histórica y desplegar una enorme erudición, no rehúye conectar con el presente y los problemas más actuales. Además, el análisis de la evolución histórica de las ideas sobre trabajo/consumo improductivo acaba conllevando aludir a otras muchas cuestiones fundamentales, tales como la acumulación de capital, las crisis económicas, el cambio técnico, el capital humano, etc. Por tanto, el libro no sólo interesará a todos aquellos especialistas en historia del pensamiento económico o economía laboral, sino que también podrá atraer a los economistas en general y a los estudiosos de la ciencia política y la filosofía social. 